Article

\title{
Antibiotic Prevalence Study and Factors Influencing Prescription of WHO Watch Category Antibiotic Ceftriaxone in a Tertiary Care Private Not for Profit Hospital in Uganda
}

\author{
Mark Kizito ${ }^{1, *(\mathbb{D})}$, Rejani Lalitha ${ }^{1} \mathbb{D}$, Henry Kajumbula ${ }^{2}$, Ronald Ssenyonga ${ }^{3}$, David Muyanja ${ }^{4}$ \\ and Pauline Byakika-Kibwika ${ }^{1}$ (D)
}

1 Department of Medicine, College of Health Sciences, Makerere University, Kampala P.O. Box 7072, Uganda; rejani.lalitha@mak.ac.ug (R.L.); pbyakika@chs.mak.ac.ug (P.B.-K.)

2 Department of Microbiology, College of Health Sciences, Makerere University, Kampala P.O. Box 7072, Uganda; hkajumbula@chs.mak.ac.ug

3 Department of Epidemiology and Biostatistics, College of Health Sciences, Makerere University, Kampala P.O. Box 7072, Uganda; rssenyonga@musph.ac.ug

4 Department of Medicine, Mengo Hospital, Kampala P.O. Box 7161, Uganda; david.muyanja@mengohospital.org

* Correspondence: mkizito2@gmail.com; Tel.: +256-777525087

Citation: Kizito, M.; Lalitha, R.; Kajumbula, H.; Ssenyonga, R.; Muyanja, D.; Byakika-Kibwika, P. Antibiotic Prevalence Study and Factors Influencing Prescription of WHO Watch Category Antibiotic Ceftriaxone in a Tertiary Care Private Not for Profit Hospital in Uganda. Antibiotics 2021, 10, 1167. https:// doi.org/10.3390/antibiotics10101167

Academic Editor:

Diane Ashiru-Oredope

Received: 20 July 2021

Accepted: 13 September 2021

Published: 26 September 2021

Publisher's Note: MDPI stays neutral with regard to jurisdictional claims in published maps and institutional affiliations.

Copyright: (c) 2021 by the authors Licensee MDPI, Basel, Switzerland. This article is an open access article distributed under the terms and conditions of the Creative Commons Attribution (CC BY) license (https:// creativecommons.org/licenses/by/ $4.0 /)$.
Abstract: Background: Excessive use of ceftriaxone contributes to the emergence and spread of antimicrobial resistance (AMR). In low and middle-income countries, antibiotics are overused but data on consumption are scarcely available. We aimed to determine the prevalence and factors influencing ceftriaxone prescription in a tertiary care private not-for-profit hospital in Uganda. Methods: A cross-sectional study was carried out from October 2019 through May 2020 at Mengo Hospital in Uganda. Patients admitted to the medical ward and who had been prescribed antibiotics were enrolled. Sociodemographic and clinical data were recorded in a structured questionnaire. Bivariate and adjusted logistic regression analyses were performed to determine factors associated with ceftriaxone prescription. Results: Study participants were mostly female $(54.7 \%)$. The mean age was 56.2 years (SD: 21.42). The majority $(187,73.3 \%)$ presented with fever. Out of the 255 participants included in this study, 129 (50.6\%) participants were prescribed ceftriaxone. Sixty-five (25.5\%) and forty-one $(16.0 \%)$ participants had a prescription of levofloxacin and metronidazole, respectively. Seven participants $(2.7 \%)$ had a prescription of meropenem. Out of 129 ceftriaxone prescriptions, 31 (24.0\%) were in combination with other antibiotics. Overall, broad-spectrum antibiotic prescriptions accounted for $216(84.7 \%)$ of all prescriptions. Ceftriaxone was commonly prescribed for pneumonia (40/129, $31 \%)$ and sepsis $(38 / 129,29.5 \%)$. Dysuria [OR $=0.233,95 \% \mathrm{CI}(0.07-0.77), p=0.017]$ and prophylactic indication $[\mathrm{OR}=7.171,95 \% \mathrm{CI}(1.36-37.83), p=0.020]$ were significantly associated with ceftriaxone prescription. Conclusions: Overall, we observed a high prevalence of prescriptions of ceftriaxone at the medical ward of Mengo Hospital. We recommend an antibiotic stewardship program (ASP) to monitor antibiotic prescription and sensitivity patterns in a bid to curb AMR.

Keywords: ceftriaxone prescription; prevalence; antibiotic stewardship; Uganda

\section{Background}

Ceftriaxone is a broad-spectrum, third-generation cephalosporin antibiotic [1]. It is used in the treatment of many community and hospital-acquired infections mainly due to Streptococcus pneumoniae, Streptococcus pyogenes, Staphylococcus aureus, Escherichia coli, Neisseria meningitides, Neisseria gonorrhoeae, Proteus mirabilis, and Enterobacter spp. [1]. Indications for ceftriaxone use include acute bacterial meningitis, severe pneumonia, complicated intra-abdominal infections, pyelonephritis, severe prostatitis, and sepsis in neonates and children [2]. 
Ceftriaxone use is high in many low-income countries owing to its broad-spectrum activity, low toxicity, and cheaper cost compared with other antibiotics [3-5]. In Uganda, studies conducted in public healthcare facilities have reported high ceftriaxone prescription rates among hospitalized patients [5-7].

Unfortunately, there are reports of increasing resistance to this commonly prescribed antibiotic, and this is one of the emerging global health issues. For instance, in one review on antimicrobial resistance (AMR) covering Eastern African countries, Gram-negative and Gram-positive resistance to ceftriaxone was very high [8]. In Uganda, a summary of antimicrobial drug resistance patterns from blood cultures collected between June 2013 and October 2014 at Mulago National Referral Hospital showed high resistance of Enterobacteriaceae to ceftriaxone [9]. Furthermore, a study done at Uganda Cancer Institute among febrile cancer patients observed that Gram-negative resistance to ceftriaxone was very high [10].

To curb the increasing AMR, the World Health Organization (WHO) recommends continuous monitoring of antibiotic use [11]. Consequently, cephalosporins are frequently identified as a particular target for use evaluation and antibiotic stewardship [12].

In Uganda, similar to many other low-income countries, the private sector is increasingly becoming an important source of health care filling gaps where no or little public health care is available [13]. Half of all Ugandans (49\%) utilize the private or private-notfor-profit (PNFP) sector care [14]. Despite this, there is a paucity of data on antibiotic use in private hospitals in Uganda. This study aimed at identifying the prevalence and the factors influencing ceftriaxone prescription at a tertiary care private not-for-profit hospital in Kampala, Uganda.

\section{Methods}

\subsection{Study Setting and Design}

A cross-sectional study was carried out from October 2019 through May 2020 at the medical ward of Mengo Hospital in Uganda. Mengo Hospital is a tertiary care private notfor-profit faith-based hospital in Kampala, the capital city of Uganda, with a bed capacity of 300. The medical ward consists of 40 beds and admits an average of 8 patients in $24 \mathrm{~h}$ and 240 patients over a month.

\subsection{Data Collection}

A team of doctors conducted the study at the medical ward of Mengo Hospital. Training and piloting of the study instruments were conducted for the study team before the start of the study. The study was conducted on weekdays. Hospital files for patients admitted to the medical ward of Mengo Hospital were reviewed. Patients with an antibiotic prescription were approached for written informed consent to participate in the study. For participants who could not consent, their next of kin was approached. We administered a structured pretested questionnaire to the study participants or their next of kin to obtain information about their sociodemographic data (age, sex, address), and medical history. Physical examination was performed on all participants. The name of the antibiotic(s) prescribed and the indication(s) for the prescription at the time of admission were extracted from the files.

\subsection{Data Handling and Statistical Analysis}

We coded and double entered all variables into Epidata version 3.0, and thereafter exported it to STATA ${ }^{\circledR}$ version 14 , where the data were cleaned and analyzed. The prevalence of ceftriaxone prescription was defined as a percentage of patients with ceftriaxone prescription among the total number of patients on any systemic antibiotic. Bivariate and adjusted logistic regression analyses were performed to determine factors associated with ceftriaxone prescription. Statistical significance was set at cutoff points of 0.2 and 0.05 for bivariate and adjusted analyses, respectively. 


\section{Results}

Two hundred and seventy-three patients admitted to the medical ward of Mengo Hospital between October 2019 and May 2020 received a prescription of antibiotics. Eighteen patients were excluded; fifteen did not consent while three were below 18 years of age. Out of the 255 enrolled, 129 (50.6\%) were prescribed ceftriaxone as shown in Figure 1 below.

\section{3 patients admitted to the medical ward} and received antibiotic prescription

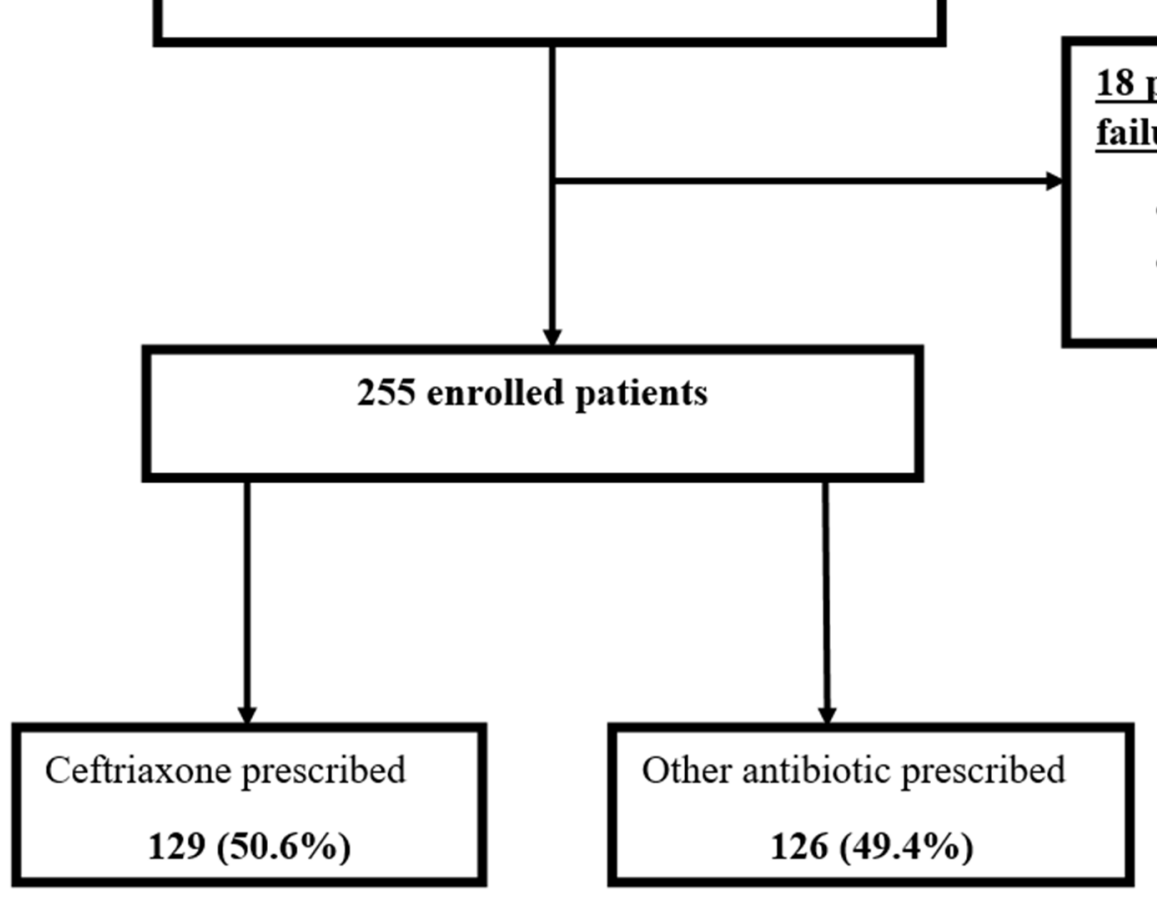

\section{8 patients- screening} failures

- 15- did not consent

- $3-<18$ years of age

Figure 1. Study profile of hospitalized patients with antibiotic prescription.

\subsection{Demographic Characteristics of Study Participants}

Among the 255 participants, $54.5 \%$ were female. The mean age was 56.2 years (SD: 21.42$)$ with the majority $(148,58 \%)$ over 50 years of age. More than half $(156,61.2 \%)$ of study participants were Baganda by tribe.

\subsection{Clinical Characteristics of Study Participants}

The majority of study participants had a fever (see Table 1). The median temperature was $36.5^{\circ} \mathrm{C}$ (IQR 36.1-37.0). The median systolic blood pressure was $125 \mathrm{mmHg}$ (IQR 104-147). One hundred and eighteen participants (46.3\%) had at least one co-morbidity. Diabetes mellitus was the most prevalent co-morbidity. Nearly a third had crackles on physical examination. More than half of study participants had received antibiotics 5 days before admission (see Table 1). 
Table 1. Clinical characteristics of the study participants.

\begin{tabular}{|c|c|c|}
\hline & Frequency (n) & Percentage $(\%)$ \\
\hline \multicolumn{3}{|l|}{ Symptoms } \\
\hline History of fever & 187 & 73.3 \\
\hline History of joint pains & 107 & 42.0 \\
\hline History of cough & 103 & 40.4 \\
\hline History of muscle pains & 91 & 35.7 \\
\hline History of vomiting & 90 & 35.3 \\
\hline History of abdominal pain & 86 & 33.7 \\
\hline History of rapid breathing & 78 & 30.6 \\
\hline History of confusion & 77 & 30.2 \\
\hline History of passing urine frequently & 37 & 14.5 \\
\hline History of wound or ulcer & 27 & 10.6 \\
\hline History of pain on passing urine & 20 & 7.8 \\
\hline History of convulsions & 19 & 7.5 \\
\hline \multicolumn{3}{|l|}{ Co-morbidities } \\
\hline Diabetes mellitus & 53 & 20.8 \\
\hline HIV & 39 & 15.3 \\
\hline Stroke & 10 & 3.9 \\
\hline Chronic lung disease & 9 & 3.5 \\
\hline Malignancy & 8 & 3.1 \\
\hline Heart disease & 7 & 2.7 \\
\hline Chronic liver disease & 5 & 2.0 \\
\hline Chronic kidney disease & 3 & 1.2 \\
\hline Use of antibiotics 5 days prior to admission & 145 & 56.9 \\
\hline \multicolumn{3}{|l|}{ Clinical Signs } \\
\hline Pallor $\$$ & 101 & 39.6 \\
\hline Lymphadenopathy & 5 & 2.0 \\
\hline Oral thrush & 8 & 3.1 \\
\hline Skin rash & 10 & 3.9 \\
\hline Wound or ulcer & 25 & 9.8 \\
\hline Bronchial breathing & 9 & 3.5 \\
\hline Crackles & 73 & 28.6 \\
\hline Rhonchi & 15 & 5.9 \\
\hline Temperature $\geq 37.5^{\circ} \mathrm{C}$ & 54 & 21.2 \\
\hline Pulse $>100$ beats $/ \mathrm{min}$ & 116 & 45.5 \\
\hline Systolic blood pressure $\leq 100 \mathrm{mmHg}$ & 51 & 20.0 \\
\hline Respiratory rate $\geq 22$ breaths $/ \mathrm{min}$ & 70 & 27.7 \\
\hline \multicolumn{3}{|l|}{ Glasgow Coma Scale (GCS) } \\
\hline$>13$ & 204 & 80.0 \\
\hline$\leq 13$ & 51 & 20.0 \\
\hline \multicolumn{3}{|l|}{$\begin{array}{l}\text { Quick Sequential Organ Failure Assessment } \\
\text { (q SOFA) score }\end{array}$} \\
\hline 0 & 127 & 49.8 \\
\hline 1 & 92 & 36.1 \\
\hline $2-3$ & 36 & 14.1 \\
\hline
\end{tabular}

\$ Pallor (Mild/Moderate 81, Severe 20).

Prevalence of Ceftriaxone Use

Out of 255 study participants, 129 [(50.6\%), 95\% CI: 44.4-56.7\%] were prescribed ceftriaxone. Of these, $40(31.0 \%)$ were prescribed for pneumonia, $38(29.5 \%)$ for sepsis, $14(10.9 \%)$ for gastroenteritis, and $14(10.9 \%)$ for urinary tract infection.

\subsection{Prescribed Antibiotics and Indications}

The most commonly prescribed antibiotics were ceftriaxone and Levofloxacin (see Table 2). Seven patients received meropenem. Of the 255 participants, 71 (27.8\%) received a combination of 2 antibiotics. Ceftriaxone and metronidazole, $20(28.2 \%)$, ceftriaxone and azithromycin, $9(12.7 \%)$, and levofloxacin and azithromycin, $6(8.5 \%)$ were the commonest combinations. Two participants received a combination of ceftriaxone, metronidazole, and 
levofloxacin. Overall, broad-spectrum antibiotic prescriptions accounted for 216 (84.7\%) of all prescriptions. Pneumonia and sepsis were the most common indications for antibiotic use (see Table 2).

Table 2. Prescribed antibiotics and indications for antibiotic use.

\begin{tabular}{|c|c|c|c|c|}
\hline & \multicolumn{2}{|c|}{ Frequency $(N=255)(n)$} & \multicolumn{2}{|c|}{ Percentage (\%) } \\
\hline \multicolumn{5}{|l|}{ Antibiotics } \\
\hline Ceftriaxone & \multicolumn{2}{|r|}{129} & \multicolumn{2}{|c|}{50.6} \\
\hline Levofloxacin & \multicolumn{2}{|r|}{65} & \multicolumn{2}{|c|}{25.5} \\
\hline Metronidazole & \multicolumn{2}{|r|}{41} & \multicolumn{2}{|c|}{16.1} \\
\hline Azithromycin & \multicolumn{2}{|r|}{27} & \multicolumn{2}{|c|}{10.6} \\
\hline Piperacillin-tazobactam & \multicolumn{2}{|r|}{16} & \multicolumn{2}{|c|}{6.3} \\
\hline Amoxicillin/clavulanic acid & \multicolumn{2}{|r|}{16} & \multicolumn{2}{|c|}{6.3} \\
\hline Gentamycin & \multicolumn{2}{|r|}{6} & \multicolumn{2}{|c|}{2.4} \\
\hline Others * & \multicolumn{2}{|r|}{28} & \multicolumn{2}{|c|}{11.0} \\
\hline \multicolumn{5}{|l|}{ Indication } \\
\hline Pneumonia & \multicolumn{2}{|r|}{74} & \multicolumn{2}{|c|}{29.0} \\
\hline Sepsis & \multicolumn{2}{|r|}{72} & \multicolumn{2}{|c|}{28.3} \\
\hline UTI & \multicolumn{2}{|r|}{37} & \multicolumn{2}{|c|}{14.5} \\
\hline Gastroenteritis & \multicolumn{2}{|r|}{33} & \multicolumn{2}{|c|}{12.9} \\
\hline Medical prophylaxis ${ }^{* *}$ & \multicolumn{2}{|r|}{16} & & \\
\hline Others *** & & 23 & & \\
\hline $\begin{array}{l}\text { * Cefuroxime (5), Meropenem (5), Flu } \\
\text { Ampiclox (1), Cefazolin (1), Cefixime } \\
\text { antibiotics were prescribed without clir } \\
\text { complicated by ascites to prevent develo } \\
\text { (5), Sinusitis (2), Tonsillitis (2), PID (1), A } \\
\text { (1), Pharyngitis (1), Rhino sinusitis (1), c }\end{array}$ & $\begin{array}{l}\text { (4) Septrin (3 } \\
\text { efpodoxime (1) } \\
\text { and/or laborato } \\
\text { t of spontaneous } \\
\text { s (1), Cholecystit } \\
\text { eptic arthritis (1 }\end{array}$ & $\begin{array}{l}\text { Ciprofloxacin (2), In } \\
\text { rythromycin (1).** } \\
\text { evidence of infection } \\
\text { acterial peritonitis. }{ }^{* * *} \\
\text { (1), Conjunctivitis (1), }\end{array}$ & $\begin{array}{l}\text { nem }(2 \\
\text { rs to cc } \\
\text { examp } \\
\text { Sinfect } \\
\text { oyema }\end{array}$ & $\begin{array}{l}\text { lbactam (2), } \\
\text { tions where } \\
\text { ver cirrhosis } \\
\text { (5), Cellulitis } \\
\text { Oral Abscess }\end{array}$ \\
\hline 3.4. Indications for Commonly Pre & ed Antibiotics & & & \\
\hline $\begin{array}{l}\text { Ceftriaxone was common } \\
(38 / 129,29.5 \%) \text {. Levofloxacin w } \\
(17 / 65,26.2 \%) \text {. Metronidazole }\end{array}$ & $\begin{array}{l}\text { rescribed fo } \\
\text { ommonly pre } \\
\text { rescribed cor }\end{array}$ & $\begin{array}{l}\text { oneumonia }(40 / \\
\text { ribed for sepsis } \\
\text { nonly for gastroe }\end{array}$ & $\begin{array}{l}31 \% \\
65,29 \\
\text { ritis }(1\end{array}$ & $\begin{array}{l}\text { nd sepsis } \\
\text { ) and UTI } \\
41,41.5 \%) \text {. }\end{array}$ \\
\hline 3.5. Factors Associated with Ceftri & Prescription & & & \\
\hline $\begin{array}{l}\qquad \text { Bivariate and multivariate } \\
\text { ceftriaxone prescription. Signif } \\
\text { rash, UTI indication, medical p } \\
\text { cantly associated with ceftriaxor } \\
\text { indication (see Table } 3 \text { ). }\end{array}$ & $\begin{array}{l}\text { ses were per } \\
\text { factors at b } \\
\text { hylactic indi } \\
\text { escription in }\end{array}$ & $\begin{array}{l}\text { rmed to identify } \\
\text { ariate analysis w } \\
\text { tion, and HIV di } \\
\text { aded dysuria and }\end{array}$ & $\begin{array}{l}\text { ors as } \\
\text { sex, } \\
\text { se. Fr } \\
\text { edical }\end{array}$ & $\begin{array}{l}\text { iated with } \\
\text { uria, skin } \\
\text { ors signifi- } \\
\text { ophylactic }\end{array}$ \\
\hline & $\begin{array}{c}\text { Adjusted } \\
\text { Odds Ratio }\end{array}$ & (95\% Confidence & erval) & $p$-Value \\
\hline Sex & & & & \\
\hline Male & 1 & & & \\
\hline Female & 0.668 & $(0.39-1.1$ & & 0.145 \\
\hline History of pain on passing urine & & & & \\
\hline No & 1 & & & \\
\hline Yes & 0.233 & $(0.07-0.77$ & & 0.017 * \\
\hline Indication & & & & \\
\hline Sepsis & 1 & & & \\
\hline Pneumonia & 1.079 & $(0.55-2.1$ & & 0.825 \\
\hline UTI & 0.989 & $(0.40-2.4$ & & 0.982 \\
\hline GIT Infection & 0.670 & $(0.29-1.6$ & & 0.391 \\
\hline Medical prophylaxis & 7.171 & $(1.36-37.8$ & & $0.020 *$ \\
\hline Others & 0.588 & $(0.22-1.5$ & & 0.296 \\
\hline
\end{tabular}


Table 3. Cont.

\begin{tabular}{ccccc}
\hline & & $\begin{array}{c}\text { Adjusted } \\
\text { Odds Ratio }\end{array}$ & (95\% Confidence Interval) & $p$-Value \\
\hline HIV & 1 & & \\
No & 1.792 & $(0.81-3.97)$ & 0.150 \\
Skin Rash & & & \\
No & 1 & $(0.53-41.22)$ & 0.165 \\
Yes & 4.671 &
\end{tabular}

\section{Discussion}

This study was carried out to investigate the prevalence of antibiotic prescription among medical inpatients in a tertiary care private not-for-profit hospital in Kampala, Uganda. The most commonly prescribed antibiotics were ceftriaxone $(50.6 \%)$, levofloxacin $(25.5 \%)$, metronidazole $(16.1 \%)$, azithromycin (10.6\%), and piperacillin-tazobactam (6.3\%). This is comparable to what has been reported from studies done in public healthcare facilities in Uganda. For instance, a study done at Mulago national referral hospital reported prescription rates of $16 \%$ and $6 \%$ for metronidazole and azithromycin, respectively [5]. Similar results have also been reported in Tanzania [15], Ethiopia [16], and Egypt [17]. Studies investigating antibiotic prescription patterns in public healthcare facilities in Uganda have reported prescription rates for ciprofloxacin at $10.2 \%$ [18] and 19\% [5]. A higher levofloxacin prescription rate in this study could likely be attributed to a change in antimicrobial susceptibility patterns. Ceftriaxone, metronidazole, azithromycin, and piperacillin-tazobactam are all listed on the 21st WHO model list of essential medicines 2019 [19] and the ministry of health essential medicines list for Uganda 2016 [20], tools designed to facilitate the appropriate use of antibiotics. Thus, the antibiotic prescription culture at Mengo Hospital is fairly adherent to international and local recommendations. Importantly, levofloxacin, the second most commonly prescribed antibiotic in this study is not listed on these lists. This highlights the need for an antibiotic prescription guideline at this facility in accordance with national and international guidelines to reduce irrational use of levofloxacin, a WHO Watch category antibiotic.

In this study, the indications for antibiotic use were pneumonia (29\%), sepsis $(28.2 \%)$, urinary tract infection (UTI) $(14.5 \%)$, gastroenteritis $(13 \%)$, and central nervous system (CNS) infection (2\%). Pneumonia was the most common indication for antibiotic use in this study probably because a significant proportion $(46.7 \%)$ of our study participants were over 60 years and therefore more predisposed to pneumonia [21]. Urinary tract infections are also common in this age group [22]. Our findings are in agreement with what has been reported in other studies $[4,16,23,24]$. A report by the Uganda National Academy of Sciences on antibiotic resistance in Uganda showed that pneumonia, septicemia, acute diarrhea, and urinary tract infections were the leading bacterial infections among hospitalized patients in Uganda [24]. Another retrospective study investigating the trends of admissions and case fatality rates among medical in-patients at a tertiary hospital in Uganda showed that pneumonia, sepsis, and gastroenteritis were among the leading causes of admissions to the infectious disease wards for a period between January 2011 and December 2014 [23]. Our findings are consistent with findings from studies done in Tanzania [15], Ethiopia [2,16], Eriteria [25], the Netherlands [26], and the US [27,28].

One in every two patients admitted to the medical ward of Mengo Hospital were prescribed ceftriaxone. This is a high prescription rate of ceftriaxone given that it belongs to the watch WHO group of antibiotics that have a high resistance potential and should not be prescribed routinely [29].Ceftriaxone is among the most commonly utilized antibiotics owing to its high potency, a wide spectrum of activity, and a low risk of toxicity [2]. It is used to treat different types of bacterial infections including pneumonia, abdominal, skin and soft tissue, and urinary tract infections [30]. It has the advantage of wide coverage of 
pathogens, easy administration as it is once-daily dosing-limiting the nursing time needed and a low cost compared with many other antibiotics [31,32]. This probably explains its high prescription rate in this study.

Not surprisingly, studies done in other public healthcare facilities in Uganda have shown a relatively high extent of ceftriaxone prescription; for instance, in a study from a tertiary care hospital in Kampala, the ceftriaxone prescription rate was 43\% [7] and $66 \%$ [5]. Similar studies done in public healthcare facilities in other parts of Uganda such as Mbarara [33], and Bwindi [6] have reported relatively high ceftriaxone prescription rates of $77.7 \%$ and $45 \%$, respectively. Similarly, studies were done in private healthcare facilities in Ethiopia-49\% [34], Pakistan-46\% [35], and Bangladesh-50\% [36]; countries with social and economic indicators of development similar to those of Uganda [37] have also reported a relatively high ceftriaxone prescription rate.

Thus, generally, the observed ceftriaxone use in the present study is irrationally high as this drug should only be used in confirmed severe infections. Overuse of ceftriaxone contributes to antibiotic resistance [38]. To reduce ceftriaxone use and mitigate the rapid development of $\mathrm{AMR}$, hospital antimicrobial stewardship programs should impose and enforce prescription restrictions, set up antibiotic consumption surveillance systems, and deliver appropriate education campaigns to prescribers. Stewardship will increase knowledge on resistance patterns to secure other low-spectrum antibiotics that can still be effectively used. Notably, there is no available published data on resistance rates of bacteria to ceftriaxone at Mengo Hospital. However, studies done in other public healthcare facilities in Uganda have reported resistance rates of $64-66 \%$ for Escherichia coli $[9,10]$ and $85-100 \%$ for Klebsiella pneumoniae $[9,10]$. It is likely that the resistance rates of bacteria to ceftriaxone at Mengo Hospital are similarly high.

We further investigated factors that may influence ceftriaxone prescription. Factors that were significantly associated with ceftriaxone use included a history of pain on passing urine (dysuria) and medical prophylactic indication. Attending clinicians were $76 \%$ less likely to prescribe ceftriaxone to patients with dysuria compared with those with no dysuria. It is not surprising that participants with dysuria were less likely to be prescribed ceftriaxone by the attending clinicians. Dysuria is a well-recognized symptom of urinary tract infections [39]. International [40] and local [41] guidelines recommend nitrofurantoin monohydrate and fluoroquinolones as the first line in the treatment of both uncomplicated and complicated urinary tract infections (acute pyelonephritis), respectively, in adults, and therefore it is likely that clinicians followed these guidelines. Clinicians were seven times more likely to prescribe ceftriaxone for medical prophylaxis compared with sepsis. In our study, medical prophylaxis referred to conditions where antibiotics were prescribed without clinical and/or laboratory evidence of infection for example ceftriaxone prescribed for patients with liver cirrhosis complicated by ascites without evidence of infection to prevent development of spontaneous bacterial peritonitis or antibiotics prescribed for patients with diabetes mellitus and hyperglycemia but no evidence of infection. This implies that whenever clinicians assess patients and find no evidence of infection, they are likely to prescribe ceftriaxone for prophylaxis. This is probably because it is a broadspectrum antibiotic with activity against a wide range of pathogens. Moreover, qualitative studies done in other healthcare facilities revealed that sometimes clinicians prescribe antibiotics for fear of bad outcomes [42-44]. It is therefore likely that ceftriaxone prescribed for medical prophylaxis was unnecessary. Notably, prophylactic use of antibiotics is a potential driver of antimicrobial resistance [45-48] which is associated with adverse outcomes. This highlights the importance of having a local prescription guideline and whenever appropriate the need to wait for laboratory results before choosing the best antimicrobial therapy.

A strength of this study is that data were collected from a private tertiary care facility, and it could be one of the first studies investigating ceftriaxone prescription in such a setting. This could imply and depict the real practice in many private tertiary hospitals in Uganda. Therefore, our paper presents data from an area and setting of the world with 
limited available data. We believe it adds valuable information to antibiotic prescribing and stewardship in private healthcare facilities in low-income countries. Results from this study were presented to clinicians and stakeholders at Mengo Hospital and an antimicrobial stewardship committee was set up to promote appropriate antibiotic use at Mengo Hospital.

However, we acknowledge the inherent weaknesses of this study in that first, the prescriptions were strictly based on the physicians' clinical acumen. Second, there are other factors we could not investigate such as influence from pharmaceutical and health insurance companies. It would be important to explore the contribution of these factors toward excessive use of antibiotics in private tertiary healthcare facilities in Uganda. Additionally, this was a single site study and therefore more data may need to be collected from other sites before generalizing the results.

\section{Conclusions}

Prevalence of ceftriaxone prescription was high in this hospital, mainly for pneumonia and sepsis. We recommend an ASP to monitor antibiotic prescription and sensitivity patterns in a bid to curb AMR.

Author Contributions: The study concept and design were by M.K., H.K., R.L. and P.B.-K., M.K. and D.M. collected the data. M.K. and R.S. analyzed the data. All authors have read and agreed to the published version of the manuscript.

Funding: This study was funded through a grant from Merck KGAA to the Merck-Makerere College of Health Sciences Antimicrobial Research Program.

Institutional Review Board Statement: The study was conducted according to the guidelines of the Declaration of Helsinki, and approved by the Institutional Review Board (or Ethics Committee) of SCHOOL OF MEDICINE RESEARCH AND ETHICS COMMITTEE (protocol code REC REF 2019-081 and date of approval 9 May 2019).

Informed Consent Statement: Informed consent was obtained from all subjects involved in the study.

Data Availability Statement: The datasets used and/or analyzed during the current study are available from the corresponding author on reasonable request.

Acknowledgments: We are indebted to the staff and patients of the medical ward of Mengo Hospital who participated in the study. We thank Moses Grace Kintu for his assistance in data collection.

Conflicts of Interest: The authors declare no conflict of interest.

\section{Abbreviations}

$\begin{array}{ll}\text { AMR } & \text { Antimicrobial resistance } \\ \text { ASP } & \text { Antibiotic Stewardship Program } \\ \text { BSI } & \text { Bloodstream infections } \\ \text { CDC } & \text { Centers for Disease Control and Prevention } \\ \text { C. difficile } & \text { Clostridium difficile } \\ \text { ESBL } & \text { Extended spectrum beta-lactamase } \\ \text { IV } & \text { Intravenous } \\ \text { GIT } & \text { Gastrointestinal } \\ \text { MRSA } & \text { Methicillin-resistant Staphylococcus aureus } \\ \text { USA } & \text { United States of America } \\ \text { UTI } & \text { Urinary tract infection } \\ \text { VRE } & \text { Vancomycin-resistant Enterococci } \\ \text { WHO } & \text { World Health Organization }\end{array}$




\section{References}

1. Katzung, B.G. Basic and Clinical Pharmacology, 14th ed.; McGraw Hill Professional: New York, NY, USA, 2017.

2. Ayele, A.A.; Gebresillassie, B.M.; Erku, D.A.; Gebreyohannes, E.A.; Demssie, D.G.; Mersha, A.G.; Tegegn, H.G. Prospective evaluation of Ceftriaxone use in medical and emergency wards of Gondar university referral hospital, Ethiopia. Pharmacol. Res. Perspect. 2018, 6, e00383. [CrossRef] [PubMed]

3. Sileshi, A.; Tenna, A.; Feyissa, M.; Shibeshi, W. Evaluation of ceftriaxone utilization in medical and emergency wards of Tikur Anbessa specialized hospital: A prospective cross-sectional study. BMC Pharmacol. Toxicol. 2016, 17, 7. [CrossRef] [PubMed]

4. Sonda, T.B.; Horumpende, P.G.; Kumburu, H.H.; van Zwetselaar, M.; Mshana, S.E.; Alifrangis, M.; Lund, O.; Aarestrup, F.M.; Chilongola, J.O.; Mmbaga, B.T.; et al. Ceftriaxone use in a tertiary care hospital in Kilimanjaro, Tanzania: A need for a hospital antibiotic stewardship programme. PLoS ONE 2019, 14, e0220261. [CrossRef] [PubMed]

5. Kiguba, R.; Karamagi, C.; Bird, S.M. Extensive antibiotic prescription rate among hospitalized patients in Uganda: But with frequent missed-dose days. J. Antimicrob. Chemother. 2016, 71, 1697-1706. [CrossRef]

6. Rudd, K.E.; Tutaryebwa, L.K.; West, T.E. Presentation, management, and outcomes of sepsis in adults and children admitted to a rural Ugandan hospital: A prospective observational cohort study. PLoS ONE 2017, 12, e0171422. [CrossRef] [PubMed]

7. Kiguba, R.; Karamagi, C.; Bird, S.M. Antibiotic-Associated suspected adverse drug reactions among hospitalized patients in Uganda: A prospective cohort study. Pharmacol. Res. Perspect. 2017, 5, e00298. [CrossRef]

8. Ampaire, L.; Muhindo, A.; Orikiriza, P.; Mwanga-Amumpaire, J.; Bebell, L.; Boum, Y. A review of antimicrobial resistance in East Africa. Afr. J. Lab. Med. 2016, 5, 432. [CrossRef]

9. Kajumbula, H.; Fujita, A.W.; Mbabazi, O.; Najjuka, C.; Izale, C.; Akampurira, A.; Aisu, S.; Lamorde, M.; Walwema, R.; Bahr, N.C.; et al. Antimicrobial drug resistance in blood culture isolates at a tertiary hospital, Uganda. Emerg. Infect. Dis. 2018, $24,174-175$. [CrossRef]

10. Lubwama, M.; Phipps, W.; Najjuka, C.F.; Kajumbula, H.; Ddungu, H.; Kambugu, J.B.; Bwanga, F. Bacteremia in febrile cancer patients in Uganda. BMC Res. Notes 2019, 12, 464. [CrossRef] [PubMed]

11. World Health Organization. Antimicrobial Resistance Global Report on Surveillance: 2014 Summary; World Health Organization: Geneva, Switzerland, 2014.

12. Robertson, M.B.; Dartnell, J.G.; Korman, T.M.; Ioannides-Demos, L.L.; Kirsa, S.W.; Lord, J.A.; Munafo, L.; Byrnes, G.B. Ceftriaxone and cefotaxime use in Victorian hospitals. Med. J. Aust. 2002, 176, 524-529. [CrossRef]

13. De Costa, A.; Diwan, V. 'Where is the public health sector?': Public and private sector healthcare provision in Madhya Pradesh, India. Health Policy 2007, 84, 269-276. [CrossRef] [PubMed]

14. Ministry of Health Uganda (Ed.) Annual Health Sector Performance Report 2015/2016; Ministry of Health Uganda: Kampala, Uganda, 2016.

15. Lyamuya, F.; Sheng, T.; Mallya, R.; Uronu, T.S.; Minde, R.M.; Anderson, D.J.; Woods, C.W.; Mmbaga, B.T.; Tillekeratne, L.G. 2029. Prevalence of Antibiotic Use and Administration among Hospitalized Adult Patients at a Tertiary Care Hospital in Kilimanjaro, Tanzania. Open Forum Infect. Dis. 2019, 6, S681-S682. [CrossRef]

16. Gutema, G.; Håkonsen, H.; Engidawork, E.; Toverud, E.-L. Multiple challenges of antibiotic use in a large hospital in Ethiopia-a ward-specific study showing high rates of hospital-acquired infections and ineffective prophylaxis. BMC Health Serv. Res. 2018, 18, 326. [CrossRef] [PubMed]

17. Talaat, M.; Saied, T.; Kandeel, A.; El-Ata, G.A.A.; El-Kholy, A.; Hafez, S.; Osman, A.; Razik, M.A.; Ismail, G.; El-Masry, S.; et al. A Point Prevalence Survey of Antibiotic Use in 18 Hospitals in Egypt. Antibiotics 2014, 3, 450-460. [CrossRef]

18. Mukonzo, J.K.; Namuwenge, P.M.; Okure, G.; Mwesige, B.; Namusisi, O.K.; Mukanga, D. Over-the-counter suboptimal dispensing of antibiotics in Uganda. J. Multidiscip. Healthc. 2013, 6, 303-310. [PubMed]

19. WHO. World Health Organization Model List of Essential Medicines: 21st List 2019; World Health Organization: Geneva, Switzerland, 2019.

20. Ministry of Health Uganda. Essential Medicines and Health Supplies List for Uganda (EMHSLU); December 2016 ed.; Pharmacy, Ed.; Ministry of Health Uganda: Kampala, Uganda, 2016.

21. Henig, O.; Kaye, K.S. Bacterial pneumonia in older adults. Infect. Dis. Clin. 2017, 31, 689-713. [CrossRef]

22. Detweiler, K.; Mayers, D.; Fletcher, S.G. Bacteruria and urinary tract infections in the elderly. Urol. Clin. 2015, 42, 561-568. [CrossRef] [PubMed]

23. Kalyesubula, R.; Mutyaba, I.; Rabin, T.; Andia-Biraro, I.; Alupo, P.; Kimuli, I.; Nabirye, S.; Kagimu, M.; Mayanja-Kizza, H.; Rastegar, A.; et al. Trends of admissions and case fatality rates among medical in-patients at a tertiary hospital in Uganda; A four-year retrospective study. PLoS ONE 2019, 14, e0216060. [CrossRef]

24. UNAS. Antibiotic Resistance in Uganda: Situation Analysis and Recommendations; Uganda National Academy of Sciences; Center for Disease Dynamics, Economics \& Policy: Kampala, Uganda, 2015; p. 107.

25. Berhe, Y.H.; Amaha, N.D.; Ghebrenegus, A.S. Evaluation of ceftriaxone use in the medical ward of Halibet National Referral and teaching hospital in 2017 in Asmara, Eritrea: A cross sectional retrospective study. BMC Infect. Dis. 2019, 19, 465. [CrossRef]

26. Aabenhus, R.; Hansen, M.P.; Siersma, V.; Bjerrum, L. Clinical indications for antibiotic use in Danish general practice: Results from a nationwide electronic prescription database. Scand. J. Prim. Health Care 2017, 35, 162-169. [CrossRef]

27. Fridkin, S.; Baggs, J.; Fagan, R.; Magill, S.; Pollack, L.A.; Malpiedi, P.; Slayton, R.; Khader, K.; Rubin, M.A.; Jones, M.; et al. Vital signs: Improving antibiotic use among hospitalized patients. Morb. Mortal. Wkly. Rep. 2014, 63, 194-200. 
28. Kelesidis, T.; Braykov, N.; Uslan, D.Z.; Morgan, D.J.; Gandra, S.; Johannsson, B.; Schweizer, M.L.; Weisenberg, S.A.; Young, H.; Cantey, J.; et al. Indications and types of antibiotic agents used in 6 acute care hospitals, 2009-2010: A pragmatic retrospective observational study. Infect. Control. Hosp. Epidemiol. 2016, 37, 70-79. [CrossRef] [PubMed]

29. Klein, E.Y.; Milkowska-Shibata, M.; Tseng, K.K.; Sharland, M.; Gandra, S.; Pulcini, C.; Laxminarayan, R. Assessment of WHO antibiotic consumption and access targets in 76 countries, 2000-2015: An analysis of pharmaceutical sales data. Lancet Infect. Dis. 2021, 21, 107-115. [CrossRef]

30. Lee, H.; Jung, D.; Yeom, J.S.; Son, J.S.; Jung, S.-I.; Kim, Y.-S.; Kim, C.K.; Chang, H.-H.; Kim, S.-W.; Ki, H.K.; et al. Evaluation of ceftriaxone utilization at multicenter study. Korean J. Intern. Med. 2009, 24, 374. [CrossRef] [PubMed]

31. Lin, H.-A.; Yang, Y.-S.; Wang, J.-X.; Lin, H.-C.; Lin, D.-Y.; Chiu, C.-H.; Yeh, K.-M.; Lin, J.-C.; Chang, F.-Y. Comparison of the effectiveness and antibiotic cost among ceftriaxone, ertapenem, and levofloxacin in treatment of community-acquired complicated urinary tract infections. J. Microbiol. Immunol. Infect. 2016, 49, 237-242. [CrossRef]

32. Hurst, A.L.; Olson, D.; Somme, S.; Child, J.; Pyle, L.; Ranade, D.; Stamatoiu, A.; Crombleholme, T.; Parker, S.K. Once-daily ceftriaxone plus metronidazole versus ertapenem and/or cefoxitin for pediatric appendicitis. J. Pediatr. Infect. Dis. Soc. 2017, 6, 57-64. [CrossRef]

33. Kemigisha, E.; Nanjebe, D.; Boum, Y.; Langendorf, C.; Aberrane, S.; Nyehangane, D.; Nackers, F.; Mueller, Y.; Charrel, R.; Murphy, R.A.; et al. Antimicrobial treatment practices among Ugandan children with suspicion of central nervous system infection. PLoS ONE 2018, 13, e0205316. [CrossRef]

34. Shimels, T.; Bilal, A.I.; Mulugeta, A. Evaluation of ceftriaxone utilization in internal medicine wards of general hospitals in Addis Ababa, Ethiopia: A comparative retrospective study. J. Pharm. Policy Pract. 2015, 8, 26. [CrossRef]

35. Saleem, Z.; Saeed, H.; Hassali, M.A.; Godman, B.; Asif, U.; Yousaf, M.; Ahmed, Z.; Riaz, H.; Raza, S.A. Pattern of inappropriate antibiotic use among hospitalized patients in Pakistan: A longitudinal surveillance and implications. Antimicrob. Resist. Infect. Control. 2019, 8, 188. [CrossRef]

36. Rashid, M.M.; Chisti, M.J.; Akter, D.; Sarkar, M.; Chowdhury, F. Antibiotic use for pneumonia among children under-five at a pediatric hospital in Dhaka city, Bangladesh. Patient Prefer. Adherence 2017, 11, 1335-1342. [CrossRef]

37. Dalevska, N.; Khobta, V.; Kwilinski, A.; Kravchenko, S. A model for estimating social and economic indicators of sustainable development. Entrep. Sustain. Issues 2019, 6, 1839-1860. [CrossRef]

38. Srinivasan, A. Antibiotic Stewardship Grows Up; Elsevier: Amsterdam, The Netherlands, 2018.

39. Cortes-Penfield, N.W.; Trautner, B.W.; Jump, R.L. Urinary tract infection and asymptomatic bacteriuria in older adults. Infect. Dis. Clin. 2017, 31, 673-688. [CrossRef] [PubMed]

40. Gupta, K.; Hooton, T.M.; Naber, K.G.; Wullt, B.; Colgan, R.; Miller, L.G.; Moran, G.J.; Nicolle, L.E.; Raz, R.; Schaeffer, A.J.; et al. International Clinical Practice Guidelines for the Treatment of Acute Uncomplicated Cystitis and Pyelonephritis in Women: A 2010 Update by the Infectious Diseases Society of America and the European Society for Microbiology and Infectious Diseases. Clin. Infect. Dis. 2011, 52, e103-e120. [CrossRef]

41. Ministry of Health Uganda. Uganda Clinical Guidelines 2016; Ministry of Health Uganda: Kampala, Uganda, 2016.

42. Md Rezal, R.S.; Hassali, M.A.; Alrasheedy, A.A.; Saleem, F.; Md Yusof, F.A.; Godman, B. Physicians' knowledge, perceptions and behaviour towards antibiotic prescribing: A systematic review of the literature. Expert Rev. Anti-Infect. Ther. 2015, 13, 665-680. [CrossRef] [PubMed]

43. O'Doherty, J.; Leader, L.F.; O'Regan, A.; Dunne, C.; Puthoopparambil, S.J.; O'Connor, R. Over prescribing of antibiotics for acute respiratory tract infections; a qualitative study to explore Irish general practitioners' perspectives. BMC Fam. Pract. 2019, 20, 27. [CrossRef]

44. Yantzi, R.; van de Walle, G.; Lin, J. ‘The disease isn't listening to the drug': The socio-cultural context of antibiotic use for viral respiratory infections in rural Uganda. Glob. Public Health 2019, 14, 750-763. [CrossRef]

45. Selekman, R.E.; Shapiro, D.J.; Boscardin, J.; Williams, G.; Craig, J.C.; Brandström, P.; Pennesi, M.; Roussey-Kesler, G.; Hari, P.; Copp, H.L. Uropathogen resistance and antibiotic prophylaxis: A meta-analysis. Pediatrics 2018, 142, e20180119. [CrossRef]

46. Roldan-Masedo, E.; Sainz, T.; Gutierrez-Arroyo, A.; Gomez-Gil, R.M.; Ballesteros, E.; Escosa, L.; Baquero-Artigao, F.; Méndez-Echevarría, A. Risk factors for gentamicin-resistant E. coli in children with community-acquired urinary tract infection. Eur. J. Clin. Microbiol. Infect. Dis. 2019, 38, 2097-2102. [CrossRef] [PubMed]

47. Nisha, K.V.; Veena, S.A.; Rathika, S.D.; Vijaya, S.M.; Avinash, S.K. Antimicrobial susceptibility, risk factors and prevalence of bla cefotaximase, temoneira, and sulfhydryl variable genes among Escherichia coli in community-acquired pediatric urinary tract infection. J. Lab. Physicians 2017, 9, 156-162. [CrossRef]

48. Nieminen, O.; Korppi, M.; Helminen, M. Healthcare costs doubled when children had urinary tract infections caused by extended-Spectrum $\beta$-Lactamase-Producing bacteria. Acta Paediatr. 2017, 106, 327-333. [CrossRef] 